\title{
THE KNOWLEDGE AND ATTITUDE TOWARDS SEEKING MEDICAL CARE IN CASE OF EXPOSURE TO SEXUAL VIOLENCE AMONGST UNIVERSITY OF BENIN FEMALE STUDENTS
}

\author{
*l. Awuno, **O.F. Obuehi, **M.H. Nwankwo \\ *Department of Community Medicine, University of Benin Teaching Hospital, \\ Benin City, ${ }^{\star \star}$ Faculty of Medicine, University of Benin, Benin City.
}

\begin{abstract}
Sexual violence has been recognized as a problem that adversely affects the well being of women. Despite the increasing wave of this crime, there is gross under reporting and a poor attitude to seeking medical care by victims, making the problem to be under-estimated and poorly managed.

The objective of the study was to assess the knowledge of the students on the concept of sexual violence and determine factors that would hinder them from seeking medical care when exposed to sexual violence.
\end{abstract}

A cross-sectional descriptive study was employed in which selfadministered questionnaires were distributed to students residing in the 4 female hostels within the Ugbowo Campus of the University of Benin.

The findings from the study showed that a greater proportion of the students were not willing to seek medical care when exposed to sexual violence. Attitude of health care workers was identified as capable of discouraging the respondents from seeking medical care. Knowledge of the consequences of sexual violence and the fact that health facilities can prevent these untoward effects was identified to facilitate seeking medical care. The study concluded by advising attitudinal change by health care workers as well as public enlightenment on the problems of sexual violence and benefit of seeking medical care to address this public health problem.

\section{INTRODUCTION}

According to WHO, sexual violence is defined as any sexual act, attempt to obtain a sexual act, unwanted sexual comments or advance or acts to traffic a person's sexuality, using coercion, threats of harm or physical force, by any person regardless of their relationship but not limited to home and work. Globally, it is believed that at least one woman in five has been physically or sexually abused by a man at some time in her life ${ }^{1-3}$.

Schools especially the tertiary institutions ought to be a place for women empowerment. They should be positive places of joy, growth and creativity but often in our country they are unhappy, unsafe and violent places where rights and freedoms are violated $^{4-5}$. Sexual violence in the education sector is an un-addressed problem $^{6}$. Sexual violence has been reported as the fastest growing crime in many parts of the world ${ }^{9}$.

The prevalence of sexual violence is not known with certainty due to gross under reporting. In Nigeria it is not seen as an issue of concern for this reason ${ }^{10}$. Addressing sexual violence in the education sector hits at the intersection of human rights, public health and educational agenda. Sexual violence prevents learners from achieving their intellectual, emotional and educational 
potential. A program to prevent sexual violence and its attendant problems should be established and an integral part of such a program would be efforts to encourage victims to seek medical care cal-18. $^{11-}$.

The aim of the study is to know the knowledge and attitude of University of Benin female students towards seeking medical care in the incidence of exposure to sexual violence.

\section{MATERIAL AND METHODS}

The study was carried out in the University of Benin founded in $23^{\text {rd }}$ November, 1970, it is located in Ugbowo Egor Local Government Area of Edo State. The population of University of Benin Undergraduates is 25,000 with a female undergraduates number of 10,075 (40.3\%).

A cross sectional study was carried out between May 2005 and May 2006. The study population comprises of all female students of University of Benin Student, residing in the four female hostels within the Ugbowo Campus of the University.

Written permission was obtained from the department of Community Health and approval was sought from the hall masters and representatives of the four hostels. A sample size of 240 was used and the calculated sample size was 217. Stratified random sampling method was employed and semi - structured self administered questionnaires were used to collect the data and analysis was done using Statistical Package for Social Sciences (SPSS) Version 11.

\section{RESULT AND DISCUSSION}

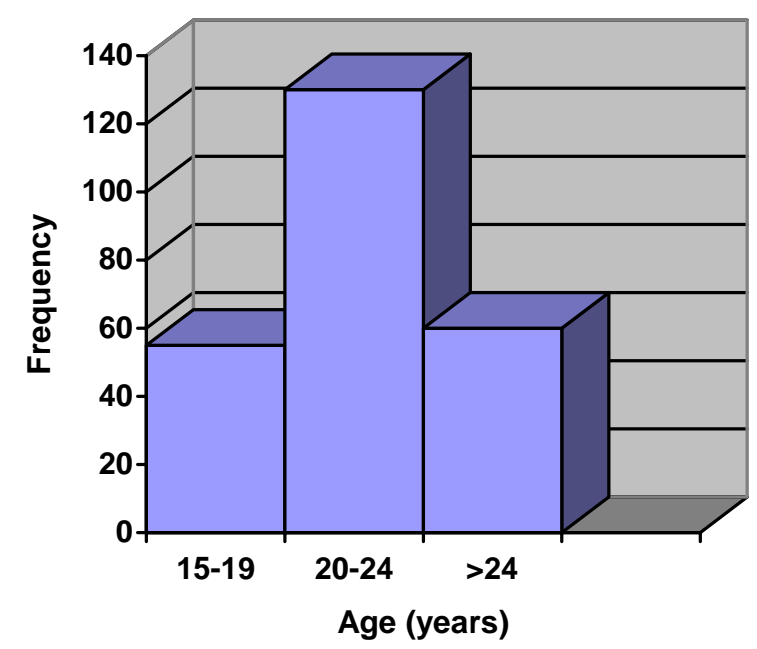

Table1: Respondents knowledge of sexual violence

\begin{tabular}{ccc}
\hline Knowledge Frequency & $\begin{array}{c}\text { Percentage } \\
\text { (\%) }\end{array}$ \\
\hline No & 7 & 2.9 \\
Yes & 233 & 97.1 \\
\hline Total & $\mathbf{2 4 0}$ & $\mathbf{1 0 0 . 0}$ \\
\hline
\end{tabular}

Almost all the respondents (97.1\%) had knowledge of sexual violence.

Table 2: Respondents knowledge of contracting HIV if rape assailant is HIV positive

\begin{tabular}{ccc}
\hline Response & Frequency & $\begin{array}{c}\text { Percentage } \\
\text { (\%) }\end{array}$ \\
\hline No & 28 & 11.7 \\
Yes & 212 & 88.3 \\
\hline Total & 240 & 100.0
\end{tabular}


Table 3: Respondents knowledge of HIV prophylaxis

\begin{tabular}{lcc}
\hline ResponseFrequency & $\begin{array}{c}\text { Percentage } \\
\text { (\%) }\end{array}$ \\
\hline No & 198 & 82.5 \\
Yes & 42 & 17.5 \\
\hline Total & $\mathbf{2 4 0}$ & $\mathbf{1 0 0 . 0}$ \\
\hline
\end{tabular}

Table 4: Relationship between attitude of health worker and going to the health facility

\begin{tabular}{lrrc}
\hline \multicolumn{1}{c}{ Attitude } & GH & NGH & Total \\
\hline UNDECIDED & 2 & 0 & 2 \\
NO & 31 & 30 & 61 \\
YES & 104 & 73 & 177 \\
\hline TOTAL & $\mathbf{1 3 7}$ & $\mathbf{1 0 3}$ & $\mathbf{2 4 0}$ \\
\hline
\end{tabular}

KEY: GH: Going to health facility $\mathrm{NGH}$ : Not going to health facility $X^{2}=3.414, d f=2, p<0.05$

There is a statistically significant difference between the attitude of health care workers and going to the health facility.

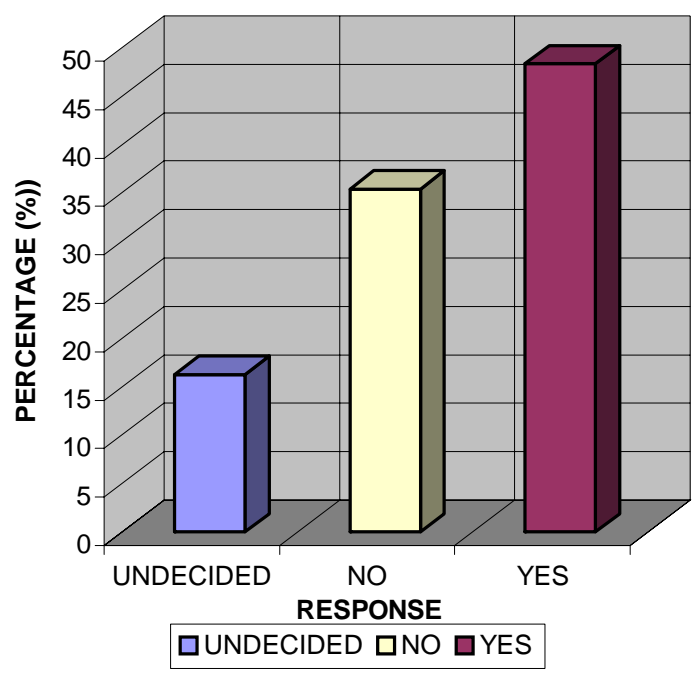

Figure II: disclosure of sexual assault to health personnel.
Less than half (48\%) of the respondents would be willing to disclose sexual assault to health personnel.

\section{DISCUSSION}

(Figure 1).

In the study carried out, majority of the respondents fell within the age range $20-24 y r s$ (55\%) this falls within the age range for the greatest exposure to sexual violence (18-24 years). Of the 240 respondents, 226 (94.2\%) were single which is considered normal for students in a higher institution. Only 14 respondents (5.8\%) were married.

A large percentage of the female students (97\%) were aware of sexual violence. However 239 respondents (99.6\%) ticked rape as a component of sexual violence, which was expected. 199 respondents of $240 \quad(82.9 \%)$ regarded unwanted sexual contact as a component of sexual violence. $53.3 \%$ (128) of the students agreed that sexual assault by one's husband was possible. However more respondents (81.7\%) believe that boyfriends are capable of sexual assault.

Less than half (48\%) of respondents were willing to disclose sexual assault to health personnel. This confirms the poor attitude towards seeking medical care in incidences of sexual assault. Furthermore, $16 \%$ of respondents were undecided about it, showing that the proportion of those unwilling to disclose sexual assault to health personnel could further rise.

Concerning benefits offered victims of sexual assault, $80 \%$ of respondents believe that pregnancy prevention and treatment of physical injury are offered, which is expected. 
$65 \%$ believe STD prevention is possible at the facility.

However a largest proportion of respondents (54\%) do not believe that HIV prevention is possible after the encounter with a positive assailant and $14.6 \%$ are aware of the possibility of prevention (Table 2). This highlights the fact that fear of contracting HIV may not be a reason to go to the health facility to obtain health care at the facility apart from those mentioned (Table 3).

Although $79 \% \quad(190)$ of the respondents believe that sexual violence had negative effects, only $68 \%$ believe that they could suffer from such negative effects if they did not go to a health facility $88 \%$ of the respondents agreed with the possibility of contracting HIV from a positive assailant and $71 \%$ believed that developing HIV infection after contact could be prevented.17.5\% (42 persons) have knowledge of HIV prophylaxis out of which only $5.4 \%$ (13 persons) had no knowledge of it. This points to the fact that prevalent knowledge of HIV prophylaxis is poor and presently therefore does not constitute a significant reason to obtain medical care.

Knowledge of Psychological effects of sexual violence and going to the health facility are not associated. This buttresses the fact that the level of knowledge of the psychological effects has not enough effect on encouraging going to the health facility.

There is an association between attitude of health workers and going to the health facility in the direction of discouraging the victims from going to the health facility on encountering sexual violence (Table 4) Figure II.

\section{CONCLUSION}

The result of the study revealed that the more than half of individuals are not willing to seek medical care in incidence of sexual violence. Greater percentages are willing to disclose the incidence to a health personnel without visiting a health facility. Attitude of the health worker is established to be capable of discouraging victims from seeking medical care.

Knowledge of the attendant problem of sexual violence and possible intervention offered by health facilities and their effectiveness influence the decision of the respondents towards seeking medical care. Those who are aware of HIV prophylaxis and its effectiveness are more willing to visit health facility. Readiness to report to police is very low in this study.

Therefore it can be concluded that attitude of health care workers and in-depth knowledge of problems of sexual violence and possible solutions that can be offered in medical facility strongly affects seeking medical care.

\section{REFERENCES}

1. United Nation Organization, Declaration on the Elimination of all forms of violence against women; UN General Assembly, 1993, New York A/RES/48/104.

2. WHO; Department of Injuries and Violence prevention, www.who.int

3. WHO, violence against women: A priority health issue, 1997, 
Geneva, World Health Organization.

4. World Bank World Development Report, 1993 Investing in Health, New York, oxford University press.

5. Thorinton, Craft, Dahberg, lynch and Baer. Best Practices of Youth violence Prevention. A sourcebook for Community Action, National Centre for Injury Prevention and Control of Centre for Disease Control, Atlanta, September 2002.

6. Adedokun O.A. Sexual Harassment In Nigeria Education settings: Preliminary Notes from a qualitative Assessment of Lagos State University, 2005, Abuja, Network for women's studies in Nigeria.

7. Pierry Marylee. Responding to sexual violence; Agenda for professionals in the commwealth, 2004, London, Great house and Hardwick.

8. Judith Mirsky Beyond victims and villains; Addressing sexual violence in the Education sector, 2003, London, Ahoeda General printing Company.

9. Schei. B; Sidenius .K; Lundvall, L; Ottersen, G;. Adult victims of Sexual assault: Acute Medical response and police reporting among women consulting at center for victims of sexual asssault. Acta Obstetricia et Gynecologica, Scandinavica, 2003, 72, 750-755.
10. Okpere E. 2005 clinical Gynecology, Benin City, Uniben press p 122.

11. Beebe D. Emergency Management of the Adult female Rape victim: American family physician June 1991, pp 181-8.

12. Taiwo O.T, African Journal for the Psychological study of social issues, 2004, 7(2), 220-236.

13. Bryout A. Hostile Hallways: The American Association of University women survey on sexual violence in American Schools; Journal of school Health 1993, 68 (3), 335-357.

14. National Council for research on women. Sexual Harassment: Research and Resources New York, 1995.

15. Neimark J. Out of Bounds: The truth about Athletes and Rape, Interactive heater.org, 2000.

16. Magid, D.J., Houry, D., The epidemiology of female rape victims who seek immediate care temporal trend in the incidence of sexual assault and acwintance rape. Journal of Interpersonal violence, 19(1), 3-12.

17. Wyatt, G.E. The socio cultural context of African American and Wute American women rape. Journal of Social (Issues 1992, 48 (1), 77-91.

18. Mama I. Violence Against Nigerian Women The Guardian on Sunday, Nigeria Dec 15, 1996. 